\title{
Mapping the spread of COVID-19 outbreak in India
}

\author{
Vanshika Bidhan ${ }^{1}$, Bhavini Malhotra ${ }^{2}$, Mansi Pandit ${ }^{3}$ and N.Latha*
}

1. Undergraduate student, B.Sc. (H) Department of Biochemistry, Sri Venkateswara College, University of Delhi, Benito Juarez Road, Dhaula Kuan, New Delhi -110021, India. Mobile- +91-9899626423, E-mailvanshikabidhan7@gmail.com

2. Undergraduate student, B.Sc. (H) Department of Statistics, Sri Venkateswara College, University of Delhi, Benito Juarez Road, Dhaula Kuan, New Delhi -110021, India. Mobile- +91-7042331006, E-mailmalhotra.bhavini@gmail.com

3. PhD Scholar, Bioinformatics Center, Sri Venkateswara College, University of Delhi, Benito Juarez Road, Dhaula Kuan, New Delhi -110021, India. Mobile-+91-9999001400, E-mail-mansi.pandit@bic-svc.ac.in

*Corresponding author. Associate Professor, Department of Biochemistry and Coordinator, Bioinformatics Center, Sri Venkateswara College, University of Delhi, Benito Juarez Road, Dhaula Kuan, New Delhi -110021, India. Mobile- +91-9891900122, E-mail- lata@bic-svc.ac.in

\section{Short title: Spread of COVID-19 infection in India}




\begin{abstract}
Background \& objectives: The global pandemic caused by novel coronavirus SARS-CoV-2 has claimed several lives worldwide. With the virus gathering rapid spread, the world has witnessed increasing number of confirmed cases and mortality rate, India is not far behind with approximately 37,000 affected individuals as on May 2, 2020. The ongoing pandemic has raised several questions which need to be answered by analysis of transmission of the infection. The data has been collected on daily basis from WHO and other sites. We have represented the data collated graphically using statistical packages, $\mathrm{R}$ and other online softwares. The present study provides a holistic overview of the spread of COVID-19 infection in India.
\end{abstract}

Methods: Real-time data query was done based on daily observations using publicly available data from reference websites for COVID-19 and other government official reports for the period $\left(15^{\text {th }}\right.$ February, 2020 to April $\left.28^{\text {th }}, 2020\right)$. Statistical analysis was performed to draw important inferences regarding COVID-19 trend in India.

Results: A decrease in growth rate of cases due to COVID-19 in India post lockdown and improvement in recovery rate during the month of April was identified. The case fatality rate was estimated to be $3.22 \%$ of the total reported cases. State-wise analysis revealed a deteriorating situation in states of Maharashtra and Gujarat among others as cases continued to increase rapidly there. A positive linear correlation between the number of deaths and total cases and exponential relation between population density and number of cases reported per square $\mathrm{km}$ was established.

Interpretation \& conclusions: Despite early preventive measures taken up by the Government of India, the increasing number of cases in India is a concern. This study compiles state-wise and district-wise data to report the daily confirmed cases, case fatalities and strategies adopted in the form of case studies. Understanding the transmission spread of SARS-CoV-2 in a diverse and populated country like India will be crucial in assessing the effectiveness of control policies towards the spread of COVID-19 infection.

Keywords: COVID-19, Data mining, Infection in India, R package, State- wise analysis, Statistical analysis 


\section{Introduction}

COVID-19 outbreak was declared as Public Health Emergency of International concern by World Health Organization on $30^{\text {th }}$ January, 2020. The epidemic began in mainland China, with a geographical focus in the city of Wuhan, Hubei in December $2019^{[1]}$. As of April $28^{\text {th }}$, 2020, 29, 54,222 cases and 2, 02,597 deaths due to coronavirus disease 2019 (COVID-19) caused by the novel severe acute respiratory syndrome coronavirus 2 (SARS-CoV-2 had been reported worldwide ${ }^{[2]}$. Clinical studies of hospitalised patients have shown that at onset of COVID-19, patients frequently show symptoms associated with viral pneumonia, most commonly fever, cough, sore throat, myalgia, and fatigue ${ }^{[3]}$.The incubation period of SARSCoV-2 can last for 2-3 weeks. The virus spread through infected person through humanhuman interaction through physical contact, coughing, sneezing and through droplets/ aerosols ${ }^{[4]}$. Till date, no specific antiviral drug or vaccine has been developed.

India is a large country with a total population of 135.26 crores. The first case of COVID-19 was reported in India in Jan 2020 in the Thrissur district of Kerala ${ }^{[5]}$. The next two cases were also reported in students who returned from Wuhan to Kerala. Since then, it has spread to other states as well. The national surveillance network, called the Integrated Disease Surveillance Programme (IDSP) started monitoring the COVID-19 cases soon after the first case $^{[6]}$. Initially, cases were reported in Delhi, Hyderabad and Jaipur in individuals who travelled back from affected countries. Subsequently, several confirmed cases were seen in Jammu, Maharashtra and Uttar Pradesh all of which were linked to people with a travel history to affected countries. Consequently, several people having any travel history were quarantined in different parts of the country. The number of infected individuals increased from 1000 to 20,000 within a span of 20 days (end March- mid April) ${ }^{[7-8]}$. As of $28^{\text {th }}$ April 2020, the Ministry of Health and Family Welfare have confirmed a total of 31,324 cases, 7,747 recoveries (including 1 migration) and 1008 deaths in the country ${ }^{[9]}$. The most severely affected regions of the country include Maharashtra with over 9000 cases, Gujarat and Delhi having more than 3000 cases each, Rajasthan, Tamil Nadu, Madhya Pradesh and Uttar Pradesh having more than 2000 cases ${ }^{[9]}$. The central as well as state governments have taken several measures to address the pandemic. These include implementation of a strict lockdown to ensure social distancing, longer quarantine period for suspected individuals, provision of essential services to all, efficient healthcare and management system. The Ministry of Electronics and Information Technology has also launched a smart phone application called Aarogya Setu ${ }^{[10]}$ to help in "contact tracing and containing the spread" of COVID-19 pandemic in the nation.

The rapid human-to-human spread of virus across regions prompts concerns regarding transmission rate, treatment strategies and preventive measures required. The present study aims at providing detailed analysis of factors influencing the spread of pandemic across India. For this purpose, real-time analysis of epidemiological data in public domain was carried out $\left(15^{\text {th }}\right.$ of February to $28^{\text {th }}$ of April, 2020). Several websites such as https://www.covid19india.org/, https://coronavirus.jhu.edu/map.html provide updated data on COVID-19. Also, websites hosted by the Indian government such as 
https://www.mohfw.gov.in/, https://www.mygov.in/covid-19/ support information on COVID-19 cases along with providing citizens with all necessary measures and guidelines to be followed to ensure safety and prevention from infection. Using such resources, the daily case detection changes were tracked and total number of cases, deaths and recoveries were noted. In a similar manner, the state-wise data was also reported. Furthermore, the study highlights the effect of factors such as population density on the recoveries and deaths due to COVID-19. The study presents an overview of the dynamics of COVID-19 infection across India and the effect of policies in controlling the spread of disease.

\section{Methodology}

\section{Data Retrieval}

Real-time data query and compilation was done based on daily observations. This study focused on analysis of COVID-19 data available in the public domain such as reference websites for COVID-19, official reports from government websites, and news from websites that quoted government statements. Data on cumulative as well as daily new confirmed cases, recoveries, deaths, total tests conducted in different states and districts of India was obtained for a period of more than 2 months ( $15^{\text {th }}$ of February, 2020 to $28^{\text {th }}$ of April, 2020). The demographic data (total population, total land area, and population density) was extracted from 2011 census of India. Data on age classification of infected patients and deceased patients in Delhi was retrieved from Delhi government's Health Department's website. The data also included number of deceased patients with comorbidities. Table I enlists all the data sources used.

Table I: List of sources for real-time data query

\begin{tabular}{|c|l|}
\hline S.No. & \multicolumn{1}{|c|}{ Data Source } \\
\hline 1. & https://howindialives.com/gram/metrics.php \\
\hline 2. & https://www.covid19india.org/ \\
\hline 3. & https://www.coronatracker.com/country/in \\
\hline 4. & https://www.mohfw.gov.in/ \\
\hline 5. & https://coronavirus.jhu.edu/map.html \\
\hline 6. & http://censusindia.gov.in/2011-Common/CensusData2011.html \\
\hline 7. & esop.gov.in/static/PDF/GSDP/statewise-data/statewisedata.pdf \\
\hline 8. & http://mospi.nic.in/sites/default/files/publication_reports/SelectedSocioEconomicStat \\
\hline 9. & isticsIndia2017_27oct17.pdf \\
\hline 10. & https://www.mygov.in/corona-data/covid19-statewise-status/ \\
\hline 11. & https://dashboard.kerala.gov.in/ \\
\hline 12. & https://arogya.maharashtra.gov.in/1175/Novel--Corona-Virus \\
\hline 13. & http://www.rajswasthya.nic.in/ \\
\hline 14. & http://hmfw.ap.gov.in/ \\
\hline 15. & https://stopcorona.tn.gov.in/ \\
\hline 16. & https://www.wbhealth.gov.in/pages/corona/ \\
\hline 17. & http://dgmhup.gov.in/en/default \\
\hline
\end{tabular}




\begin{tabular}{l|l|}
\hline 18. & http://health.delhigovt.nic.in/wps/wcm/connect/doit_health/Health/Home/Covid19/B \\
ulletin+Apr+2020 \\
\hline 19. & https://www.aninews.in/ \\
\hline
\end{tabular}

\section{Data Analysis}

$\mathrm{R}$ programming language and environment (developed at Bell Laboratories by John Chambers and colleagues) is free, open-source software used for statistical computing. It provides a wide variety of statistical (linear and nonlinear modelling, classical statistical tests, time-series analysis, classification, clustering) and graphical techniques, and is highly extensible ${ }^{[11-12]}$. Developed by Microsoft, Microsoft Excel is another powerful tool used for calculations, graphing tools, pivot tables etc. Datawrapper, is an open source data visualization platform, used to create simple, correct and embeddable charts quickly. The data retrieved for the study was processed using R version 3.6.1, Microsoft Excel 2016, and online data analysing tool Datawrapper ${ }^{[13]}$. Maps were plotted using E-Maps (Excel Maps).

\section{Results}

As of April $28^{\text {th }} 2020$, the Ministry of Health and Family Welfare confirmed a total of 31,324 cases, 7,747 recoveries and 1,008 deaths spread across various regions in the country (Figure 1). It was reported that in India every infected person passed on the virus only to another 1.7 people on an average. This referred to as the Reproduction Number $R_{0}$, was comparatively lower than Iran $\left(\mathrm{R}_{0}=2.73\right)$, Italy $\left(\mathrm{R}_{0}=2.34\right)$ and China $\left(\mathrm{R}_{0}=2.14\right)^{[14]}$.

\section{Cumulative (total) cases, recoveries and deaths}

We define total confirmed cases as the number of total positive cases for SARS-CoV-2 infection in the country. The number of active cases is the currently infected cases, i.e., without the case resulting into any recovery or death. Closed cases include the total recoveries and total deaths, as these cases are not infected currently.

\begin{tabular}{|l|l|}
\hline Total confirmed cases $=$ Active cases + Closed Cases \\
\hline Closed cases $\quad$ = Total number of recoveries $\&$ deaths \\
\hline
\end{tabular}

From the collated data, we analysed that the total cases doubled every 5 days between March 23 and March 29. There was increase in growth rate of total cases, as the cases doubled in every 4 days between March 29 and April 6. However, a slower doubling in number of cases (every 6 days) was seen from April 6, which is assumed to be the effect of nationwide lockdown on March 25. The growth rate of cases from April 24 to April 28, is 5.2\%, which means that the cases double in every 13 days. The cumulative recoveries also approximately doubled every fourth day between March 24 and April 10. Slower doubling in number of recoveries was seen between April 10 to April 25, as the recoveries doubled in every 5 days. The total deaths doubled every third day between March 24 and April 3. After April 4, a 
reduction in growth rate of deaths was observed (Figure 2). A more detailed pattern of COVID-19 during the month of April is represented in (Figure 2-c), where it is evident that the number of recoveries with respect to the total cases has increased with time.

\section{Figure 1: Map showing the spread of SARS-CoV-2 in India}

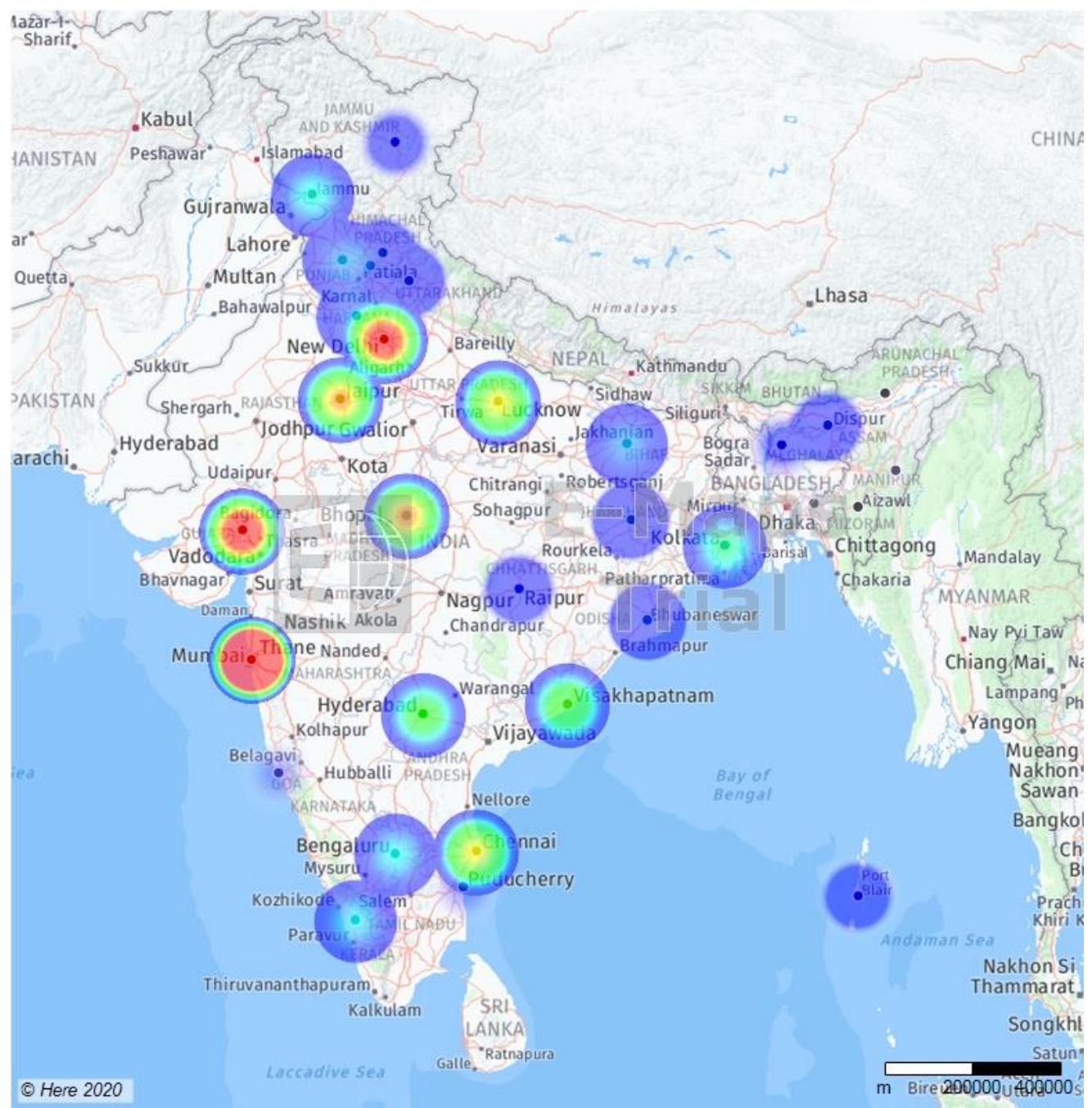

Figure 1: Spread of SARS-CoV-2 throughout India displayed through various clusters of confirmed cases and their ranges of incidence. Blue, Cyan, Green, Yellow, and Red represent $\sim$ 10, 500,1000, 2000, 3000 confirmed cases, respectively. 


\section{Figure 2: Total cases, recoveries and deaths}

a)

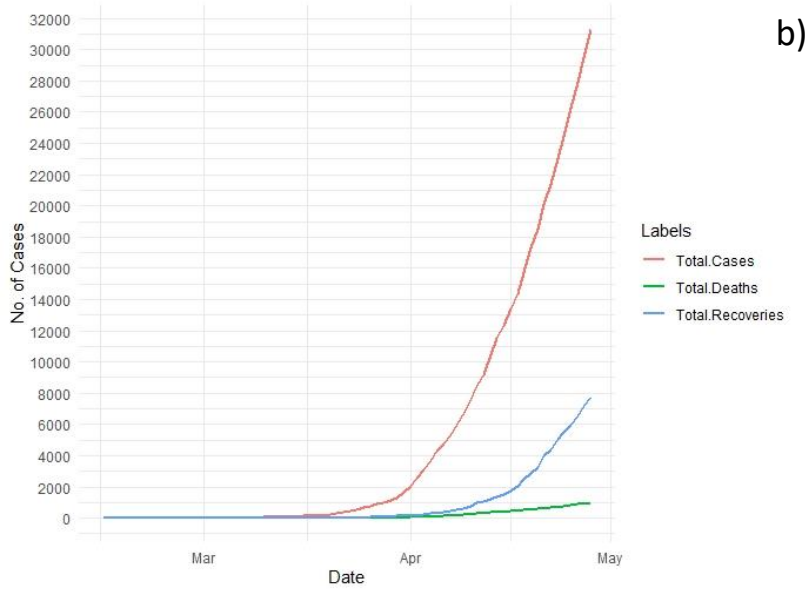

c)

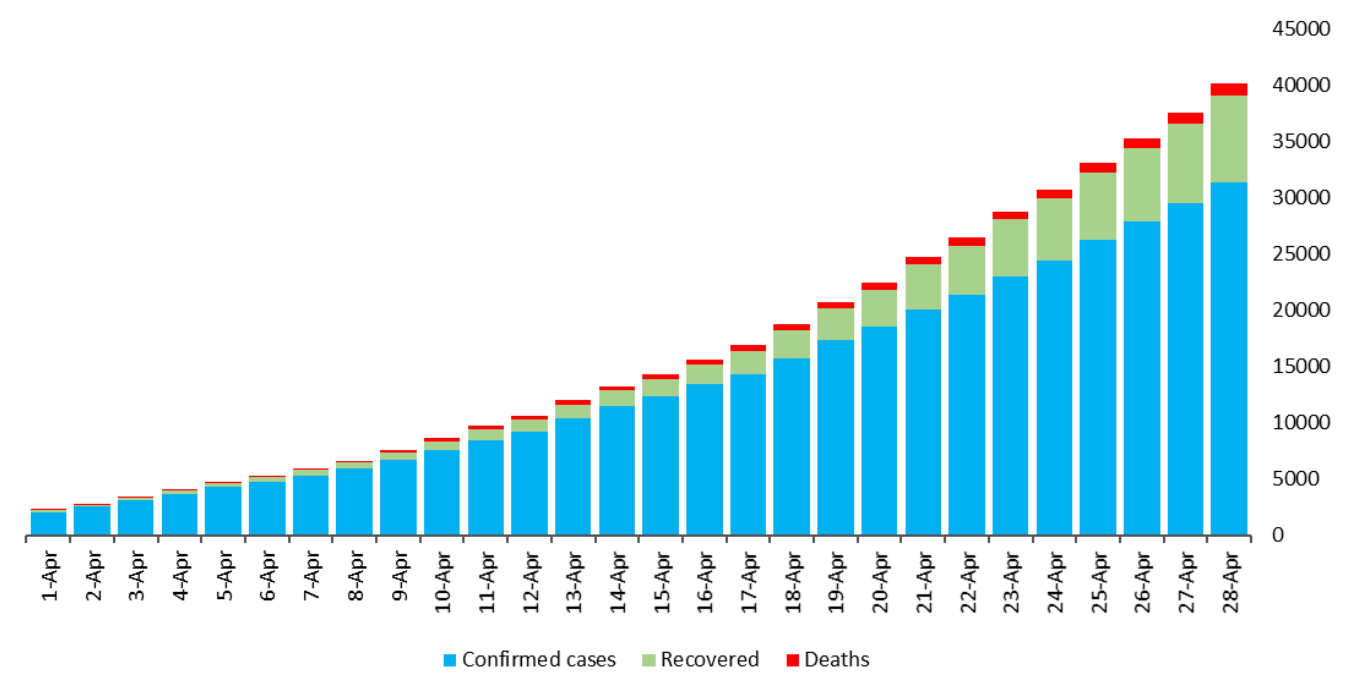

Figure 2: Date-wise data of the incidence of COVID-19 depicting cumulative number of confirmed cases (red), deaths (green) and recoveries (blue) on (a) linear scale and (b) logarithmic scale, and (c) bar chart representing number of total confirmed cases, recovered cases and number of deaths in the month of April

\section{Daily new cases, new recoveries and deaths}

As per our analysis, on an average, 423 patients were found positive for SARS-CoV-2 infection per day and the maximum numbers of cases were reported on April $28^{\text {th }}, 2020.105$ recoveries and 14 deaths were reported each day on an average. The maximum number of recoveries and deaths were reported on April $21^{\text {th }}, 2020$ and April $28^{\text {th } 2020}$, respectively (Figure 3). A comparison of the daily recoveries with daily new deaths (Figure 4) showed that with the passage of time, the growth rate of recoveries increased than the rate of deaths. 
Figure 3: Number of confirmed cases, deaths and recoveries daily

a)

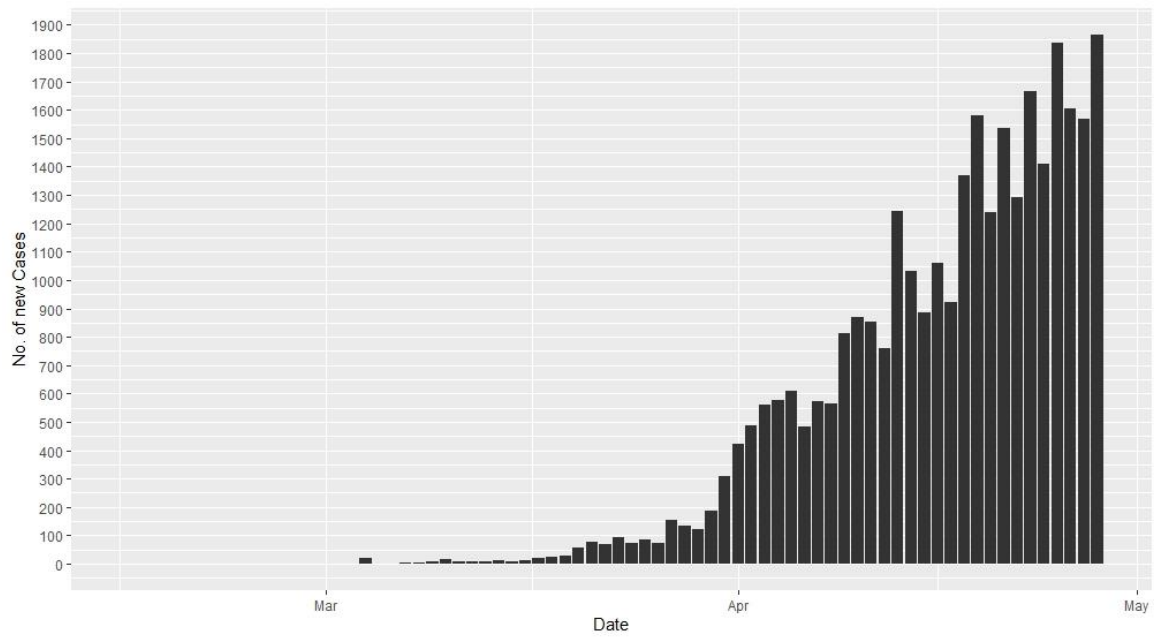

b)

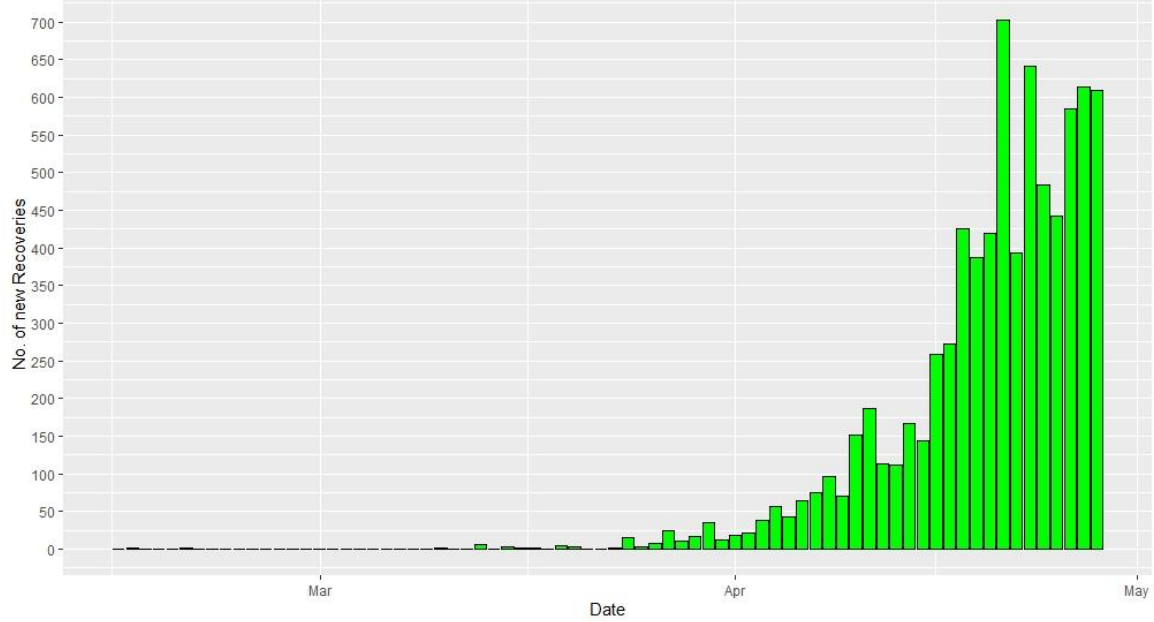

c)

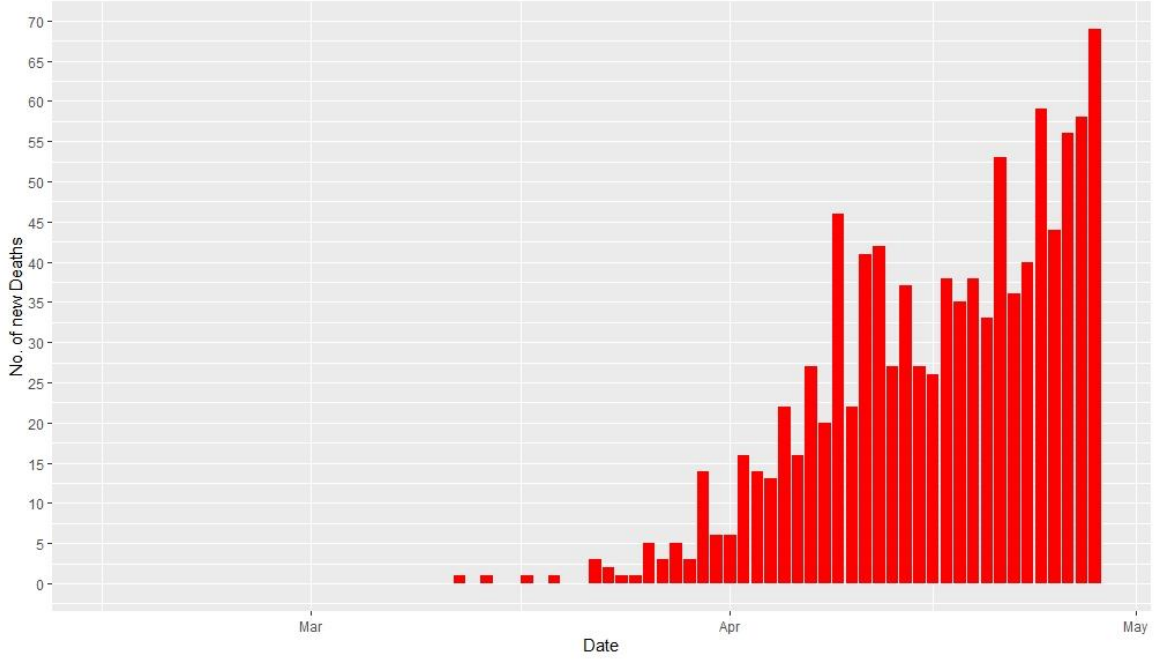

Figure 3: Graphical representation of data of daily new number of people (a) affected with COVID-19, (b) recovered from COVID-19 and (c) died due to COVID-19 against the date. 


\section{Figure 4: Outcome of cases closed daily}

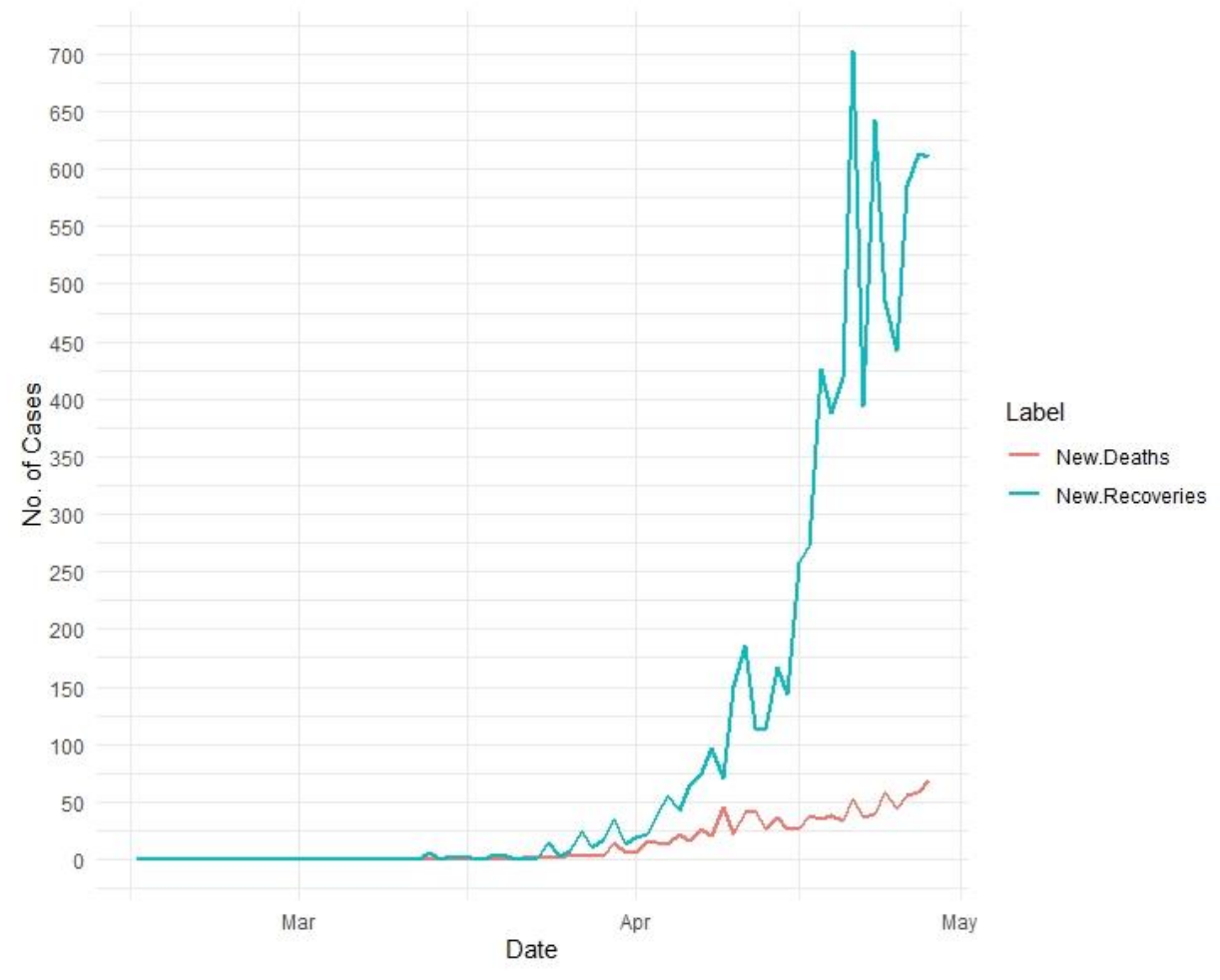

Figure 4: Graph indicating daily new deaths (red) and daily new recoveries (blue) accounting for each case closed daily.

\section{Case Fatality Rate (CFR)}

Case Fatality Rate is defined as "the proportion of cases of a specified condition that are fatal within a specified time" ${ }^{[15]}$

$\mathrm{CFR}=($ total deaths due to COVID-19 in specified time period / total number of confirmed cases of COVID-19 in same time period )* 100

As of April 28, the CFR in India was 3.22\% of total confirmed cases, $4.47 \%$ of total active cases and $11.51 \%$ of total closed cases. 22,569 cases were still open in India. The highest CFR per total cases was calculated to be $3.6 \%$ on April 12 (Figure 5). 


\section{Figure 5: Case Fatality Rate of COVID-19 in India}

a)

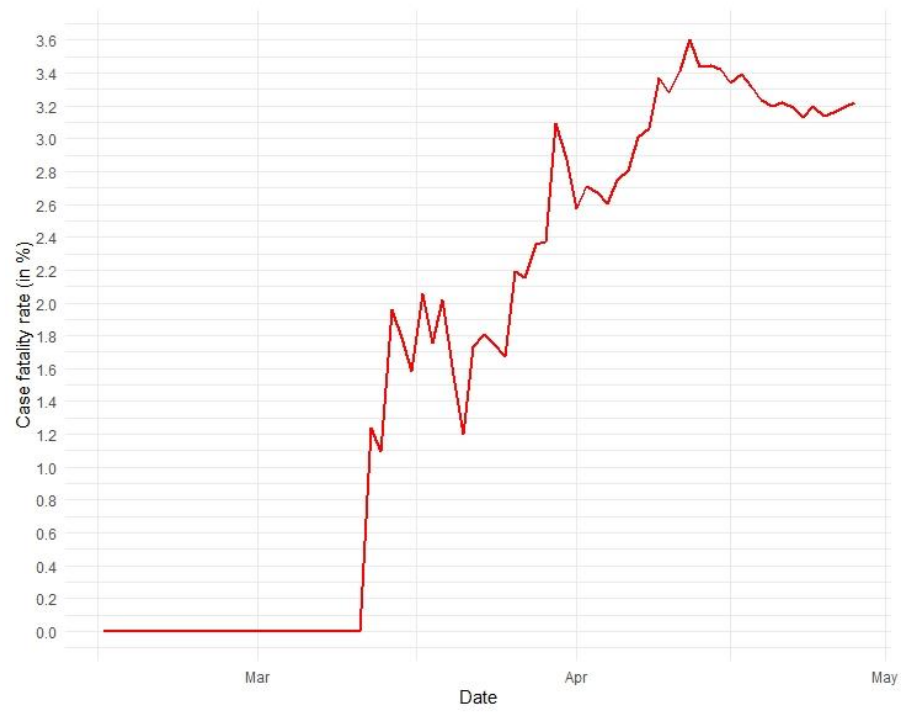

b)

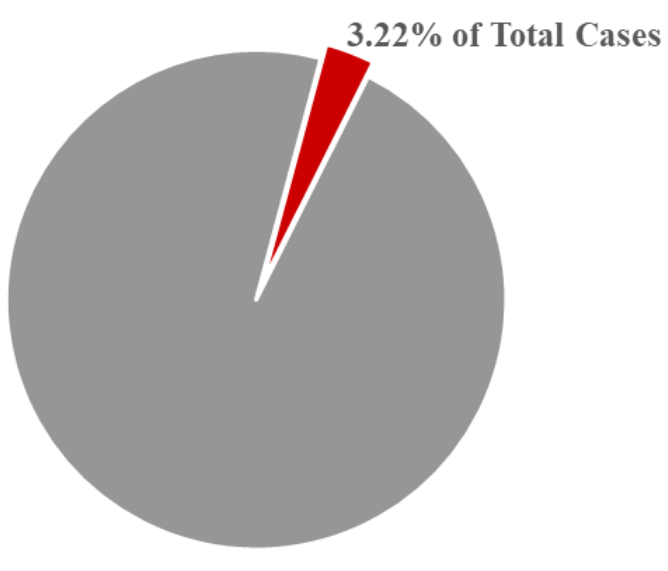

Figure 5: (a) Graph indicating date-wise CFR calculated per total confirmed cases from the onset of disease in India till April 28, and (b) pie chart depicting the percentage of the number of COVID-19 cases resulting in death in India (red) out of the total confirmed cases in India (grey), as on April 28.

\section{Recovery rate}

In our analysis, we have defined Recovery rate as the percentage of total recoveries to total number of confirmed cases. As of April 28, the recovery rate from COVID-19 in India was $24.73 \%$ of total confirmed cases, which is also the highest yet. The recovery rate per total active cases and total closed cases was $34.33 \%$ and $88.49 \%$ respectively (Figure 6). 


\section{Figure 6: Recovery Rate of COVID-19 in India}

a)

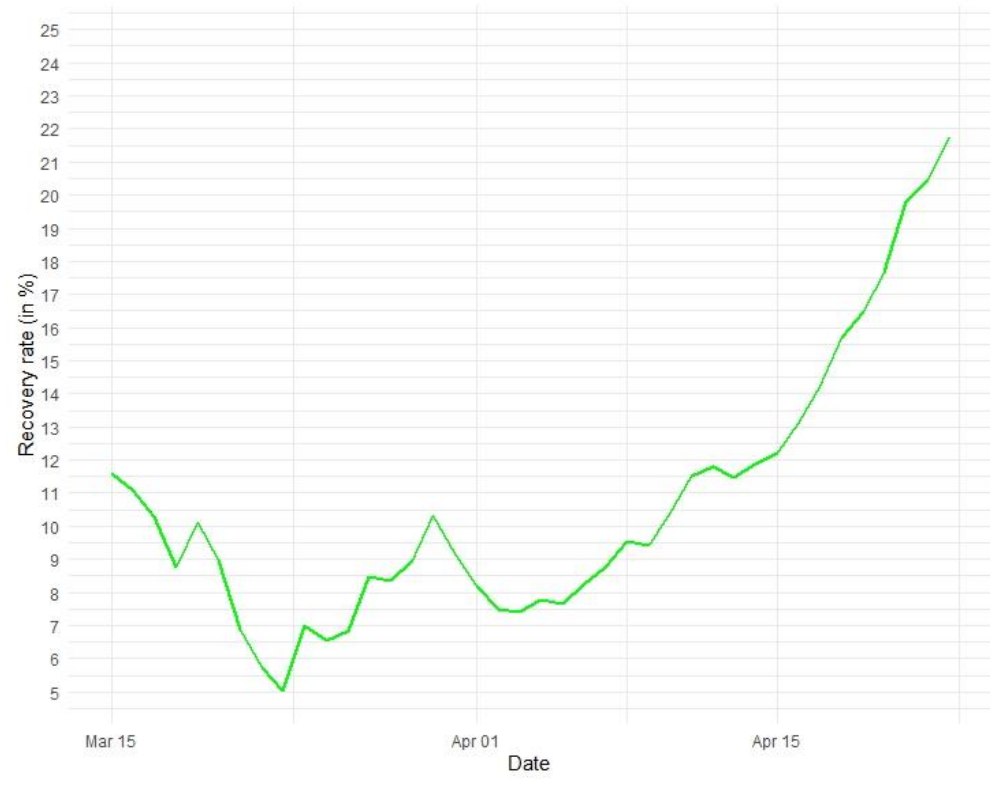

b)

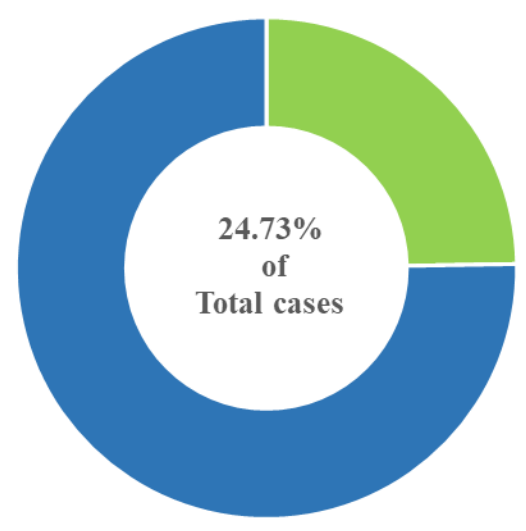

Figure 6: (a) Graph depicting percentage of recovered cases of total confirmed cases in India and (b) pie chart depicting the percentage of number of cases resulting in recovery (green) of the total number of people affected with COVID-19 in India (blue) as on April 28, 2020.

\section{State-wise data analysis of COVID-19 infection}

The state-wise analysis revealed Maharashtra state with highest number of cases $(9,282)$ as of April 28, 2020. The western state of Gujarat and the capital city of Delhi trailed behind at 3,774 and 3,314 cases respectively (Figure 7). Also, examination of the new confirmed cases showed that recovery in the states of Telangana, Tamil Nadu and Delhi improved as growth rate of cases in these states decreased while, growth rate of cases increased in Maharashtra, Gujarat, Madhya Pradesh, Rajasthan, Uttar Pradesh and Andhra Pradesh (Figure 8). Further, the total deaths in different states were studied based on the case fatality rate (CFR) (Figure 9; a). As of April 28, Meghalaya had the highest CFR of $8.33 \%$ with 1 death out of 12 positive cases in the state while, Bihar had the lowest CFR of $0.55 \%$. Since CFR accounts for the number of deaths over total number of cases, the individual state values do not provide clear idea of the death toll in different states. Figure 9; b shows the contribution of different states to National CFR (3.22\%). Maharashtra accounted for about $39.7 \%$ of national CFR, which was due to total death toll of 400 patients in Maharashtra, followed by Gujarat (18\%) with 181 deaths reported. A strong positive linear correlation between the number of confirmed cases and deaths was observed for several states (Figure10). 


\section{Figure 7: Total number of confirmed COVID-19 Cases in different States and Union territories of India (as on April 28, 2020)}

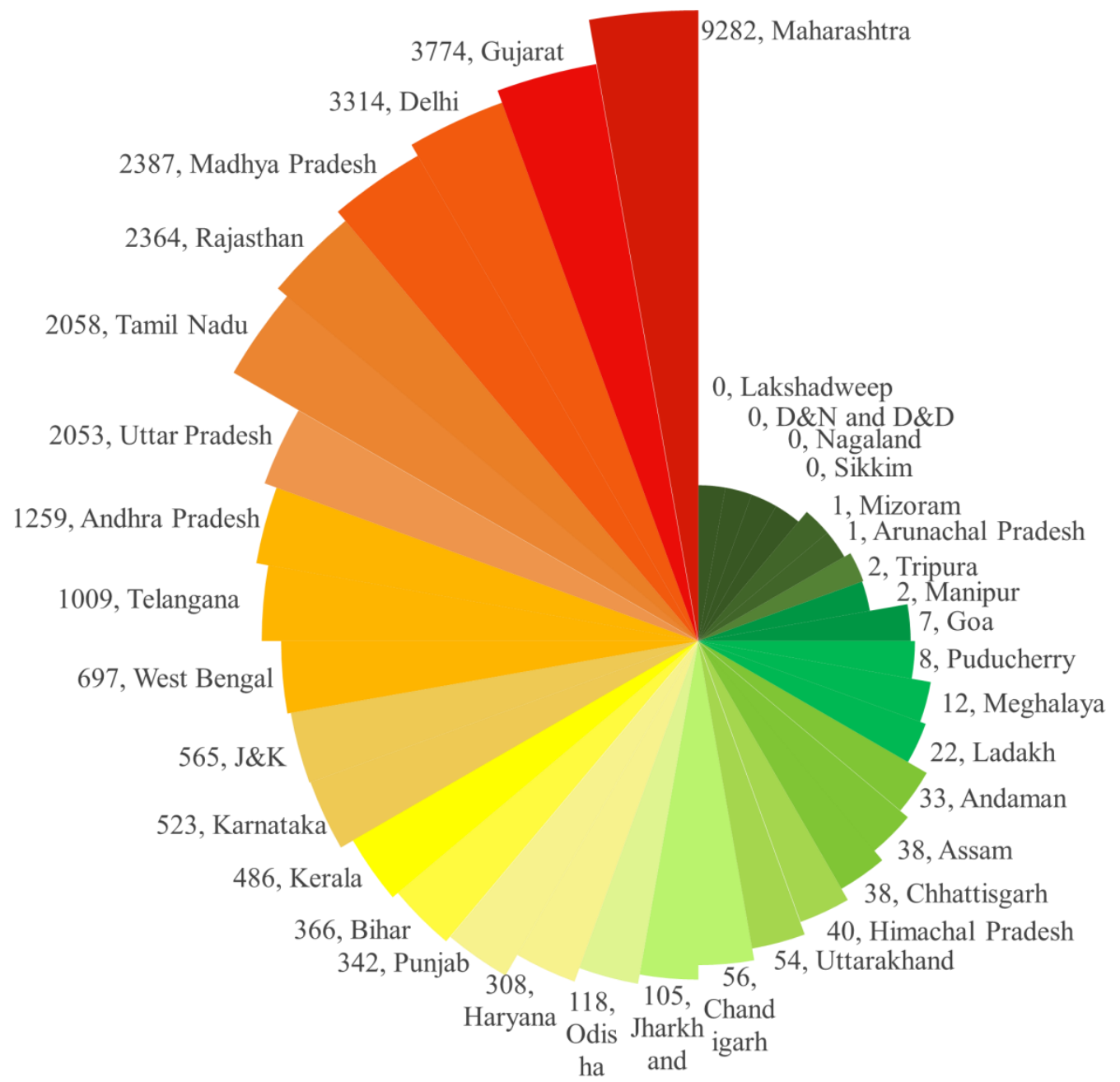

Figure 7: This image represents the state-wise incidence of COVID-19 as total number of cases in India, represented in increasing order, the states coloured in a gradient of green to red, based on data as of April 28, 2020. 
Figure 8: 5-Day moving average of new confirmed cases across Indian States with total confirmed cases greater than 1000
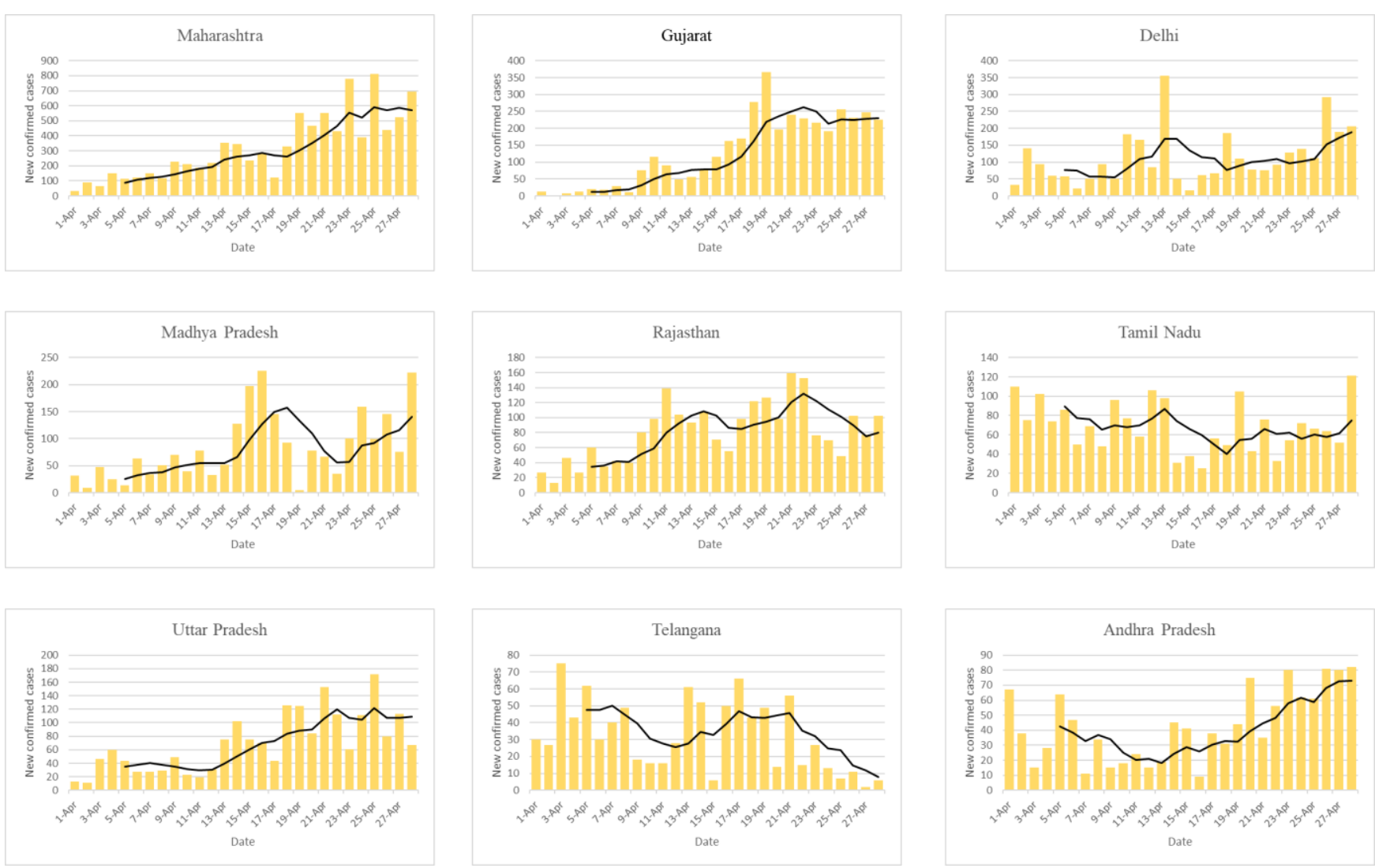

Figure 8 : Graphs depicting 5-day moving average plotted as a trendline for number of new confirmed cases (y-axis) reported over time (x-axis) in different Indian states. 
Figure 9: Analysis of the total deaths in different states

a)

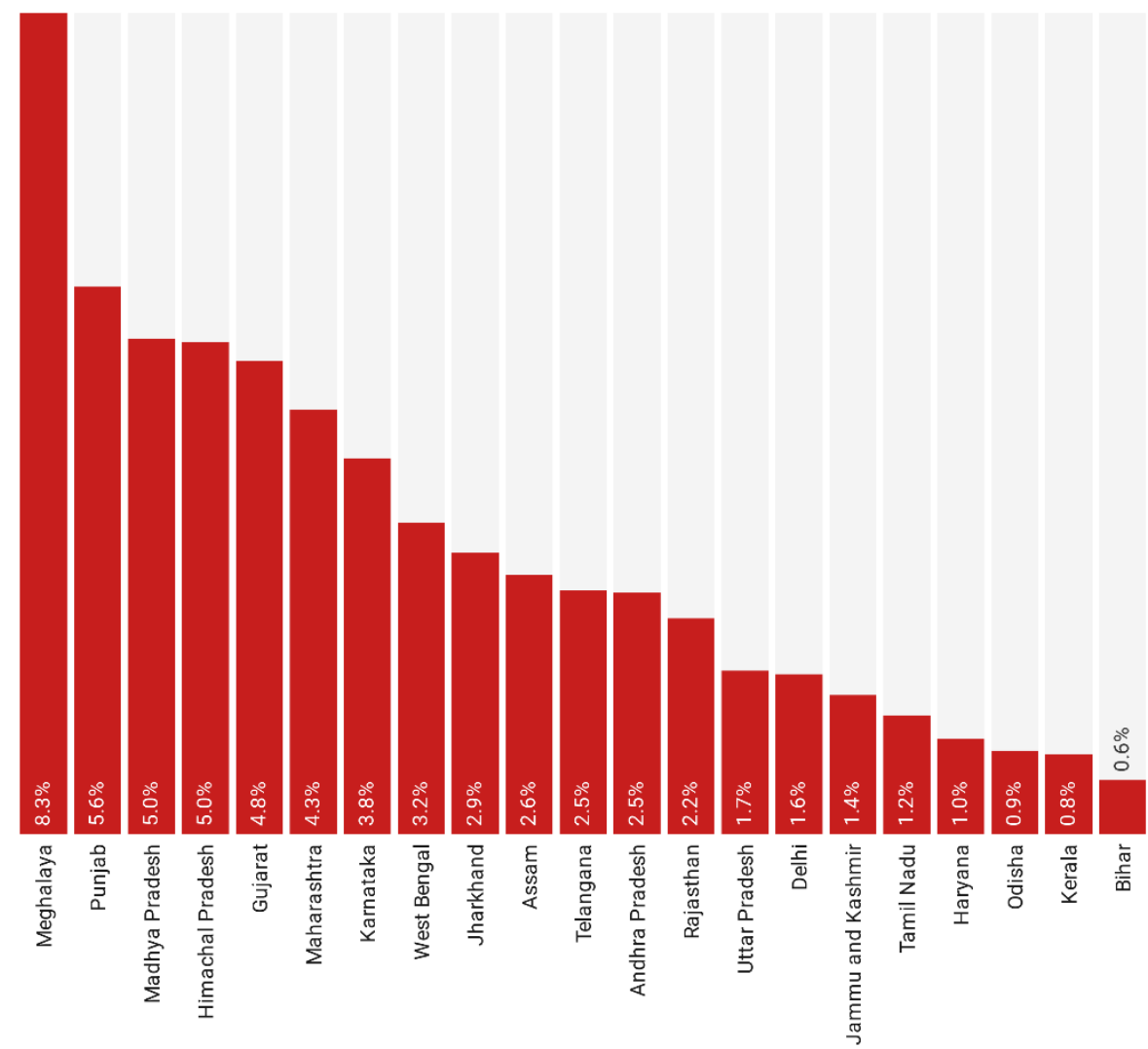

b)

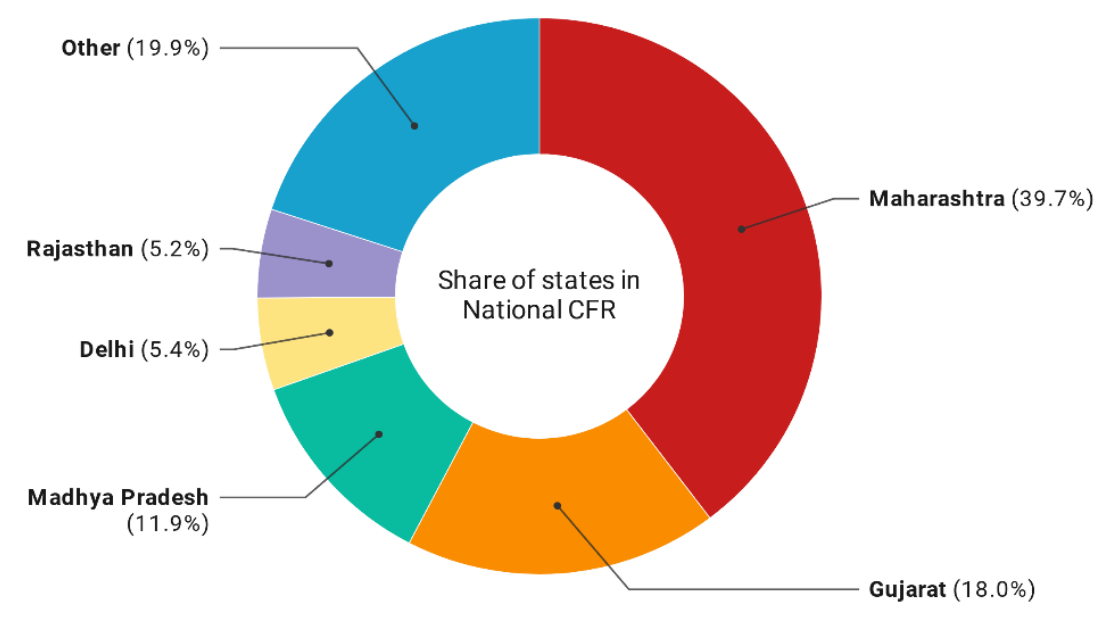

Figure 9: (a) The bar chart illustrating the CFR of COVID-19 in different Indian states, according to data as recent as April 28, 2020 and (b) pie chart depicting share of states in National Case Fatality Rate of COVID-19 in India 


\section{Figure 10: Relation between total deaths and confirmed cases}

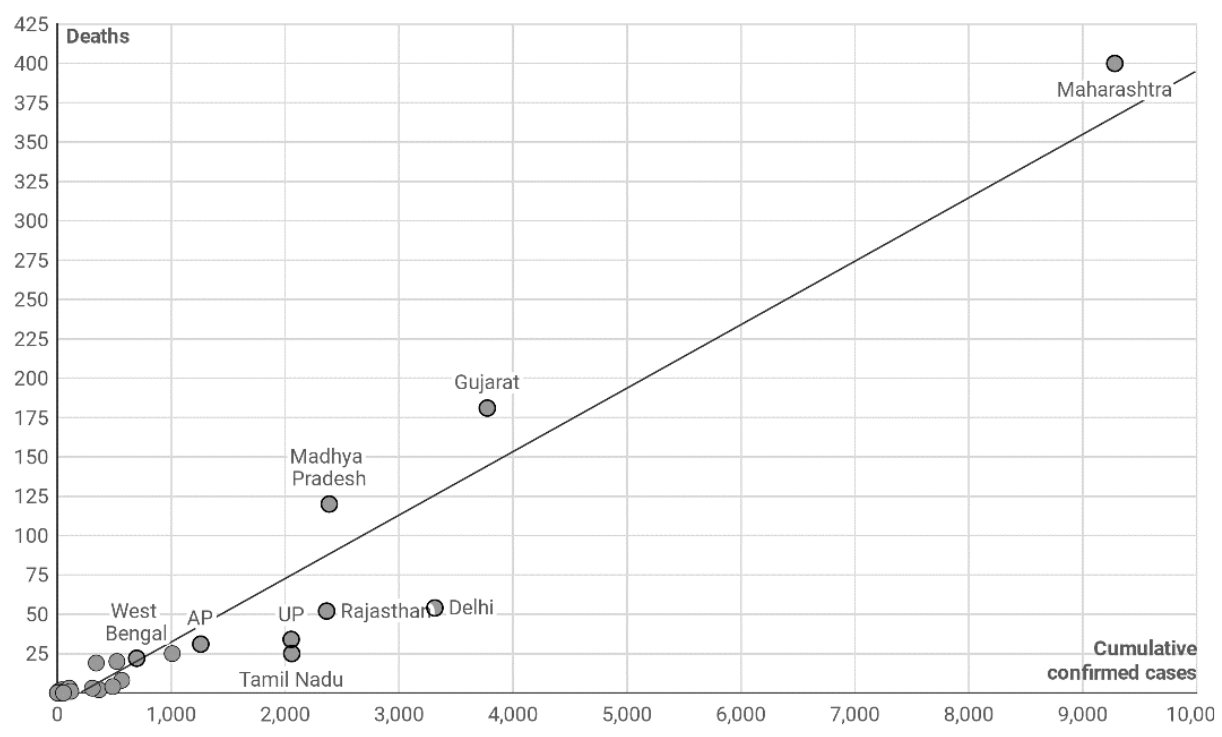

Figure 10: Plot representing relation between total confirmed COVID-19 cases and deaths in different states of India.

\section{Effect of population density}

We studied the effect of population density of a state on the number of cases and deaths reported for that state. A graph considering two variables: percentage of total cases per sq $\mathrm{km}$ area and population density of different states was plotted (Figure 11-a) which depicted that the number of cases reported was exponentially related to the population in given area. Delhi showed $223.5 \%$ cases per $\mathrm{km}^{2}$, which is equal to 9 people getting infected in an area of 4 $\mathrm{km}^{2}$. This was followed by Chandigarh, with $49 \%$ cases per $\mathrm{km}^{2}$, which approximately equals to 2 people getting infected with SARS CoV-2 in an area of $4 \mathrm{~km}^{2}$. Further, to get a clear idea of the death toll in different states, we analysed the deaths by considering the total population of the states. The death rate per million was highest in Maharashtra (3.56\%). Even though the numbers of deaths in Delhi were lower than Maharashtra, Gujarat and Madhya Pradesh, the death rate per million people was high for Delhi (3.3\%) due to its significant number of deaths over large population size, followed by Gujarat (2.99\%) and Madhya Pradesh (1.65\%) (Figure 11- b).

Also, we analysed the relation between total confirmed cases per million population and samples tested per million population (TPM) of different states. Figure 12 shows weak positive linear correlation between total cases per million population and TPM. Strong positive correlation was expected in this analysis, but the expected results could not be obtained, which is assumed to be due to the number of pending results of testing per day as the outcome of these pending results was not included in confirmed positive cases, and also 
due to the data discrepancy between tests conducted by government and private laboratories. Our analysis shows that Delhi conducted highest number of tests per million of its population i.e. 2653 TPM, followed by Tamil Nadu (1412) and Rajasthan (1348).

\section{Figure 11: Effect of state population on total cases and deaths}

a)

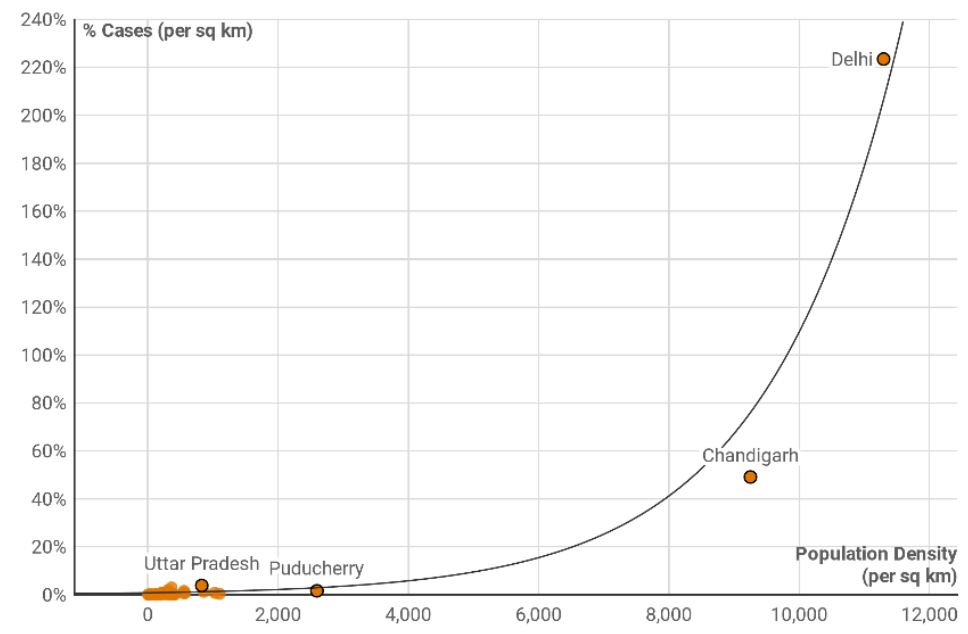

b)

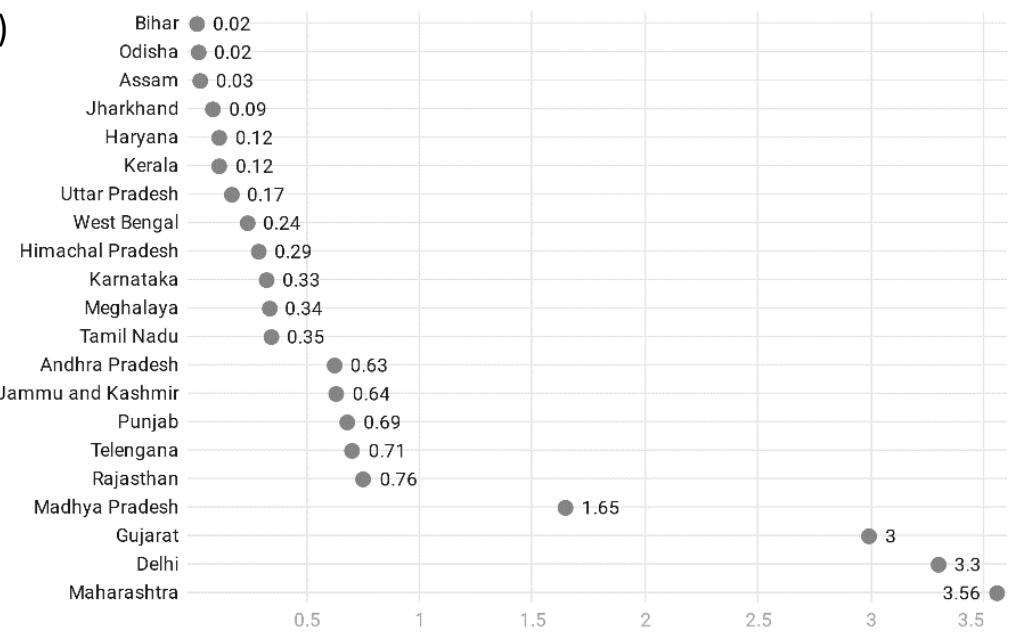

Figure 11: (a) Data of the percentage of people affected with COVID-19 (per $\mathrm{km}^{2}$ ) in different Indian states (Y-axis) versus population density in these states (X-axis) is graphically represented, and (b) chart representing COVID-19 Death Rate per million people in different states. 


\section{Figure 12: Relation between total confirmed cases and total sample tests}

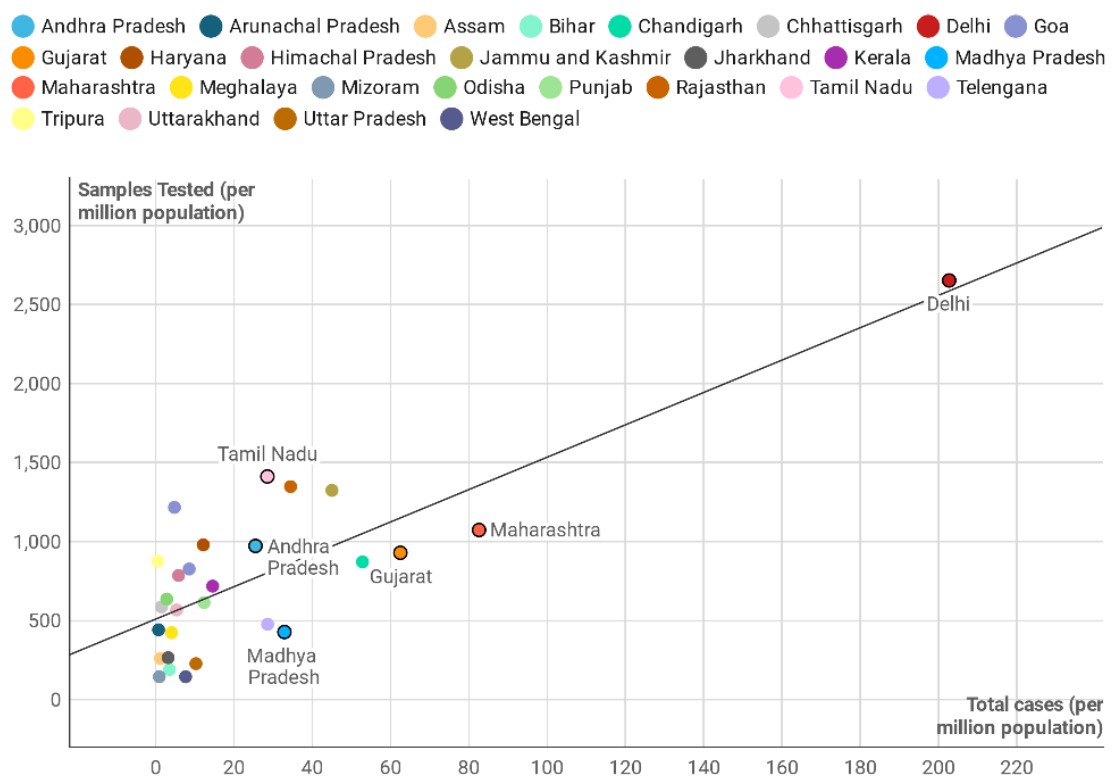

Figure 12: Graph representing data on total samples tested per million population (on y-axis) and total cases reported per million population ( $\mathrm{x}$-axis) in different states of India, as on April $28,2020$.

\section{Districtwise analysis of COVID-19 in India}

The spread of COVID-19 across India is far and wide affecting nearly all districts (Figure 13- a). The most affected districts of India included Mumbai having highest number of confirmed cases (6169), followed by Ahmedabad (2542), Indore (1372) and Pune (1174) (Figure 13-b). These observations are supported by the high population size of these districts [16] 
Figure 13: District wise classification on number of confirmed cases (as on April 28, 2020)

a)

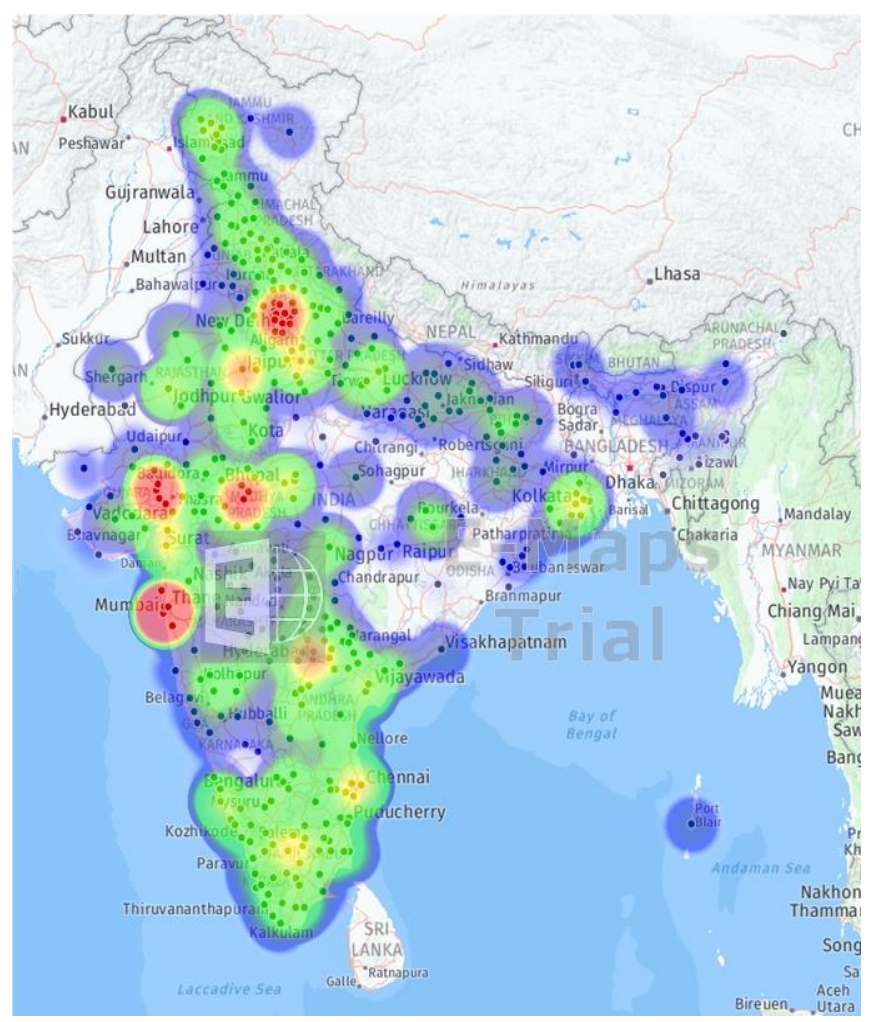

b)

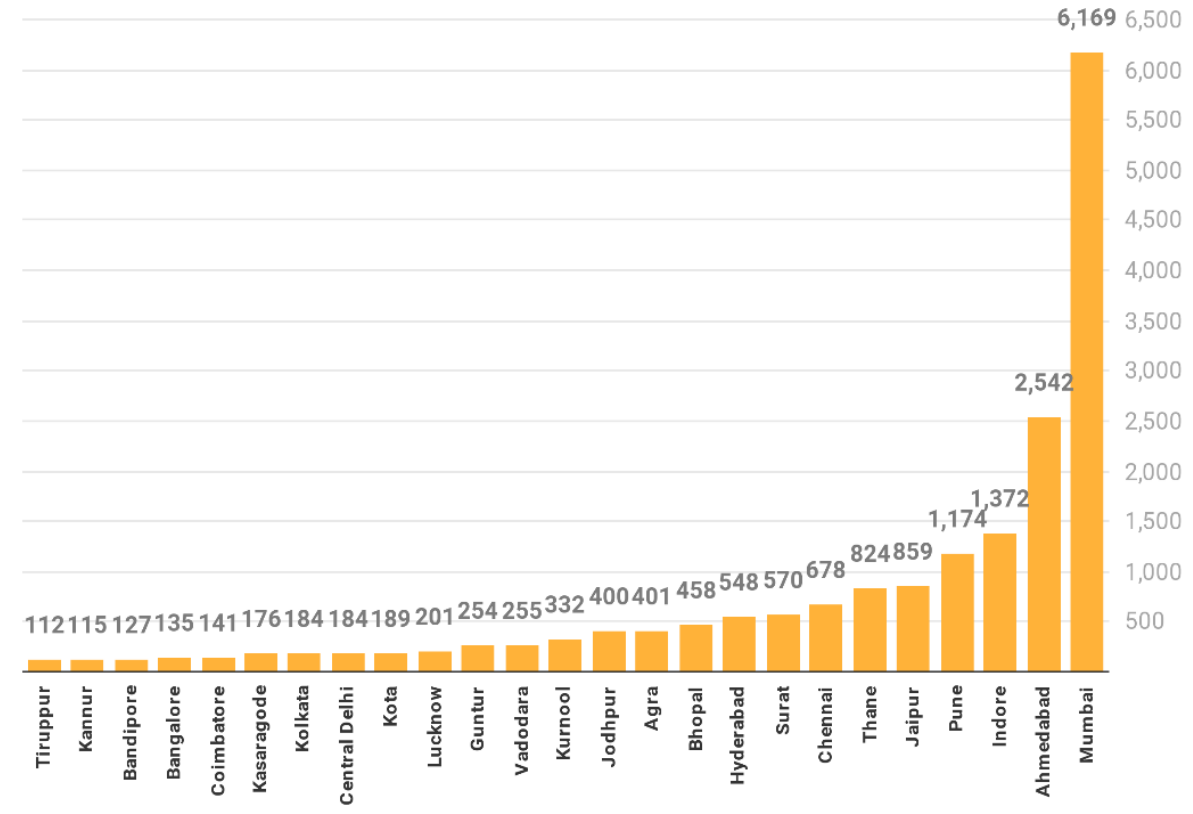

Figure 13: (a) Map showing districts of India having confirmed cases of COVID-19 (blue $\approx 5$, green $\approx 100$, yellow $\approx 400$, orange $\approx 700$, red $\approx 1000$ confirmed cases) and (b) Data of the districts reporting the highest numbers of COVID-19 cases is graphically represented, according to data as recent as April 28, 2020. 


\section{Case Study 1: Situation in the Nation's capital, Delhi}

As per our earlier analysis of sample testing and growth rate of positive cases in different states, we concluded that the increase in growth rate of cases in Delhi has improved and come down with time. It was also seen that Delhi has conducted highest number of tests per million of its population. We plotted these two variables in the Figure 14 to get a graphical visualisation of trend of TPM and total number of cases in Delhi over time. The increased testing and the strict containment plan of Delhi government with 100 containment zones ${ }^{\text {[17] }}$ has contributed to proper tracing and treatment of COVID-19 patients in the capital.

Age distribution pattern of the infected individuals was analysed for which a sample data of 3108 positive cases was collected, and it was calculated that $66 \%$ of these patients aged below 50 years, $18 \%$ of these patients aged 60 years and above, while only $16 \%$ aged between 50-59 years (Figure 15). It was thus concluded that the maximum number of patients were below 50 years of age, which is in accordance with the latest WHO situation report ${ }^{[18]}$.

A sample data of 54 deceased patients was also obtained which revealed that 10 of these deceased patients aged below 50 years, 15 aged between 50- 59 years and the maximum number, i.e. 29 deceased patients were 60 years or above (Figure 16a). This number accounts for $54 \%$ of deaths in Delhi, indicating that elder people are more susceptible to death by the disease. Out of these 54 deceased patients, 9 patients aged below 50 years, 11 patients aged between 50-59 years and 26 patients aged above 60 patients who died had comorbidities, highlighting that $85 \%$ of the deceased patients had comorbidities (Figure 16b).

\section{Figure 14: Tests per million and total positive cases in Delhi}

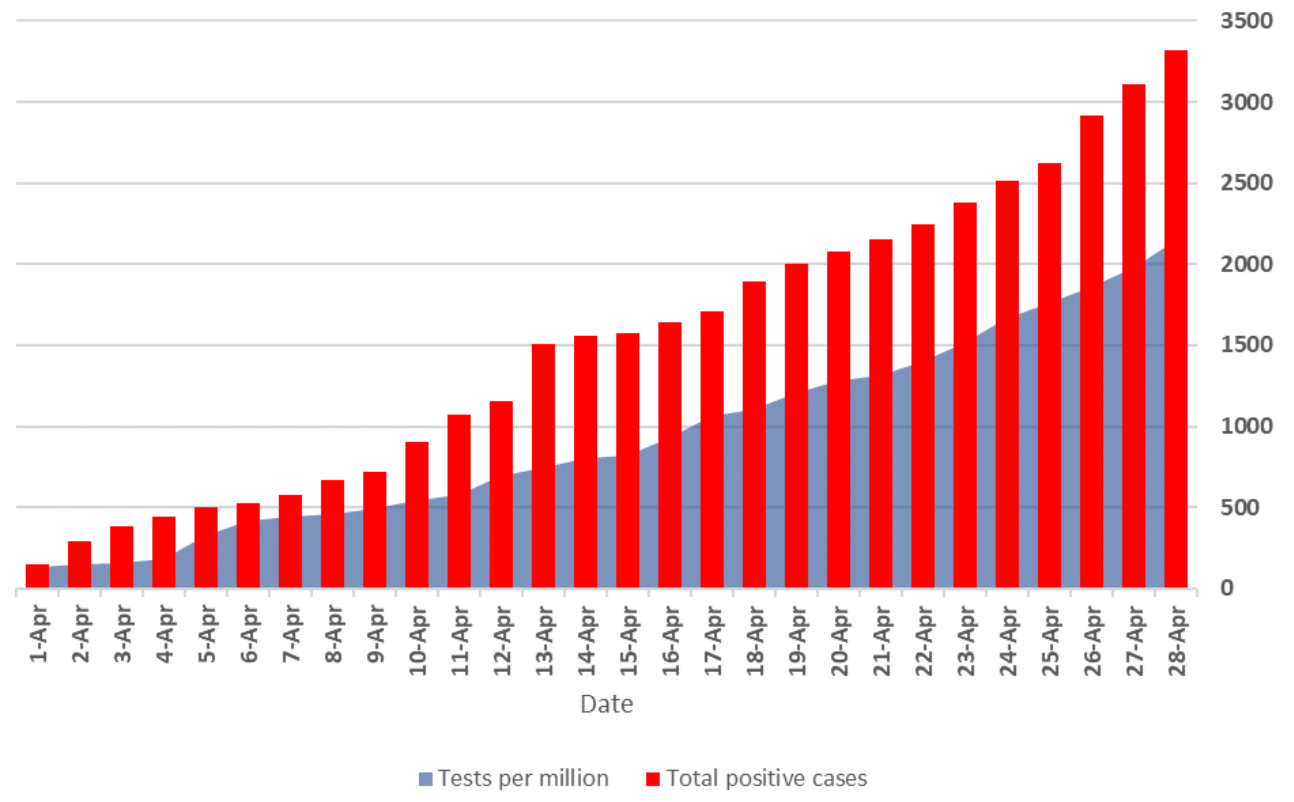

Figure 14: The graph representing tests conducted per million of population in Delhi as a proportion of the total cases observed in Delhi throughout the month of April. 
Figure 15: Age distribution based on sample of 3108 positive patients

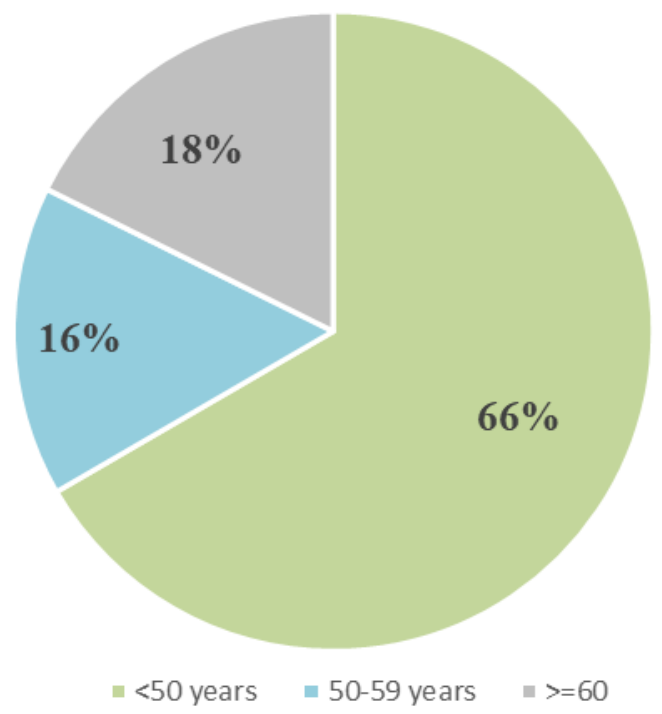

Figure 15: Pie chart depicting age of 3,108 positive patients in Delhi. Three categories were plotted $<50$ years (green), 50-59 Years (blue) and >=60 Years (grey).

\section{Figure 16: Age Classification of 54 deceased patients in Delhi}

a)

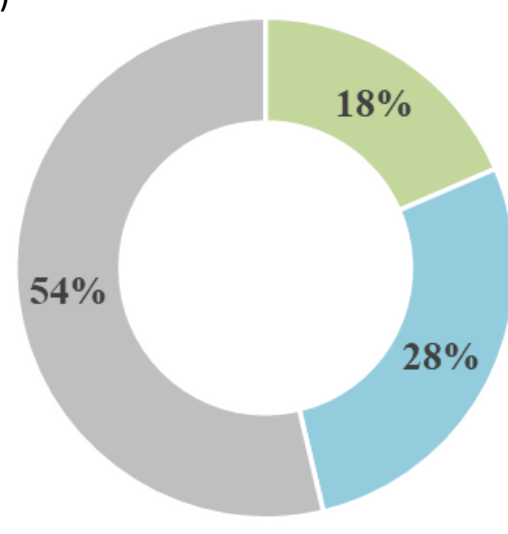

b)

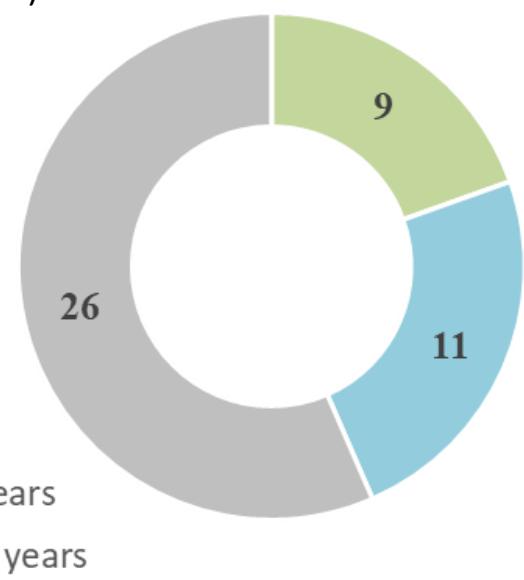

$\square=60$

Figure 16: (a) Pie chart representing age distribution of deceased patients, sample size $=54$ deceased patients and (b) pie chart representing number of patients out of 54 deceased patients who had comorbidities 


\section{Case Study 2: Effect of containment areas marked by the government}

\section{Zone 1: Kasaragod, Kerala (Kasaragod Initiative)}

Kasaragod, a district in Kerala state of South India has shown successful containment of SARS CoV-2. Figure 17 represents the 5 day moving average of new confirmed cases in the district. We analysed the data to give appropriate reasoning to the trend observed in the figure. A decrease in rise in new cases was observed on 21 March, as the Kerala government imposed complete lockdown of the district on 20 March.

On 23 March, the district reported sudden increase in the number of confirmed cases. Lockdown phase 1 was implemented on 25 March. The police force was activated for 20000 homes quarantined, COVID safety app and GIS was launched, positive cases were tagged, primary and secondary contacts were identified, road blocks were erected, villages were cut off, movement was restricted to essential services, extensive use of media was done to spread the message, WHO videos on how to observe home quarantine were made available in regional languages. Healthcare facilities were improved. Zero new cases were reported on 25 March, and epidemic act was implemented on 26 March.

33 new cases were reported on 27 March, the highest of all. In response to this sudden increase, the government implemented lockdown phase 2 on 28 March: 7 COVID containment zones (CCZs) were identified, home deliveries were started in CCZs, provision of telemedicine platform (Swaraksha Kasaragod) and new app Amrutham for home delivery was made, mobile patrols and drones were used to implement and monitor mobility.

On 30 March, the district reported 17 new cases, due to which lockdown phase 3 was implemented. All primary and secondary contacts were guided by police, surveillance of primary and secondary contacts was done by mobile beat patrolling and drone beat covering of the houses of primary and secondary contacts, violators were shifted to government quarantine, and legal action against the violator and family was taken. Due to the above containment plan and measures taken by the government, the disease was contained to a very large extent, as very few new cases were reported in April. ${ }^{[19]}$ 
Figure 17: Figure representing five day moving average of new confirmed cases in Kasaragod, Kerala

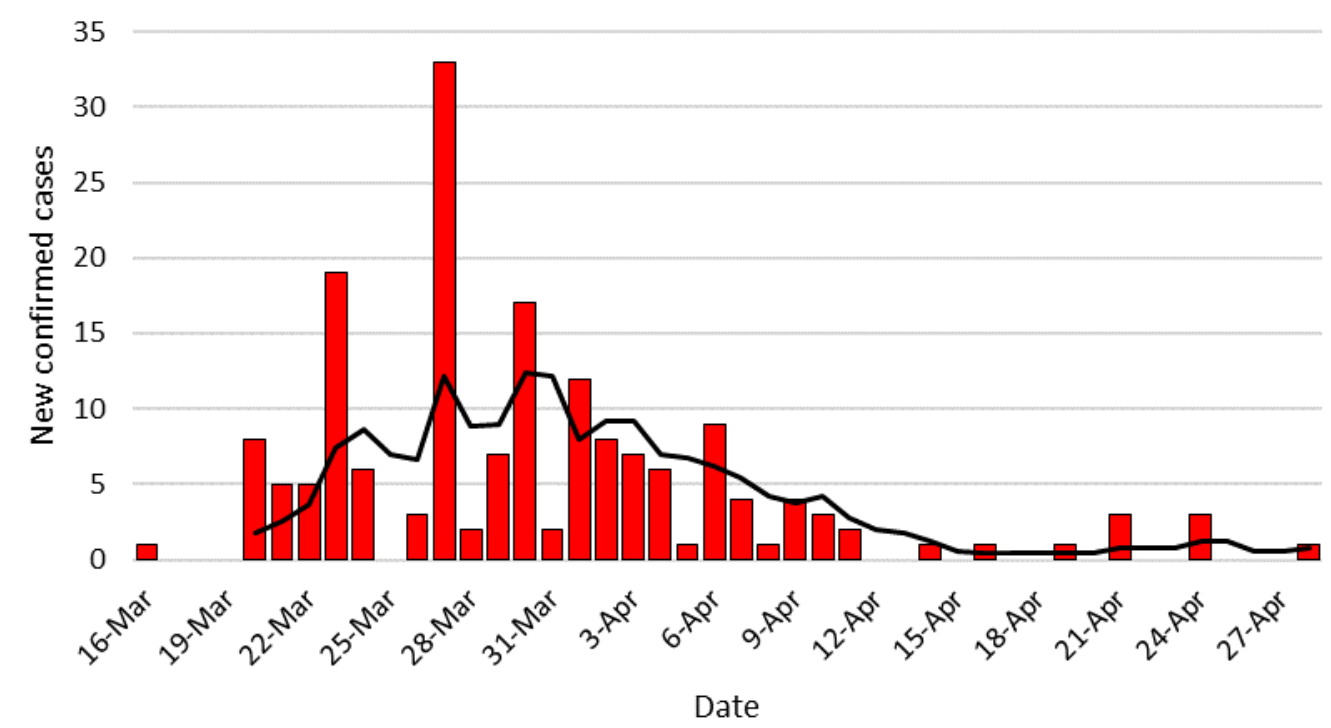

Figure 17: Data highlighting moving average of new confirmed cases over 5 days in Kasaragod, Kerala was plotted as a bar graph. The solid black line depicts the trend in occurrence of new cases by removing the noise from random fluctuations.

\section{Zone 2: Bhilwara, Rajasthan (Bhilwara Model)}

Bhilwara, a district in Rajasthan, India reported its first positive case of a doctor in a private hospital on 19 March. Since the epicentre of the outbreak was a healthcare professional, the number of cases increased to a total of 13 on March 21. By March 22 2020, the district administration in Bhilwara constituted approximately 850 teams and conducted house-tohouse surveys of nearly 3 lakh people. This helped the administration to tracing patients who tested positive. By March 26, 6445 people were kept in home quarantine. The state Health Department used an app to monitor the conditions of those under home quarantine on a daily basis along with keeping a tab on them through geographical information system (GIS). Imposing a total lockdown on the district alongwith the local police ensuring strict implementation of the curfew drastically reduced the frequency of the cases after March 30 and the district didn't report a single case on March 31. The police ensured essential supplies to the public by doorstep delivery. After March 31, only two news cases were reported from the district till April 20. These measures implemented by the district administration and Health department, contributed to the containment of the disease. What could have led to an increased number of positive cases in just few days was successfully controlled ${ }^{[21]}$. 
Figure 18: Figure representing five day moving average of new confirmed cases in Bhilwara, Rajasthan

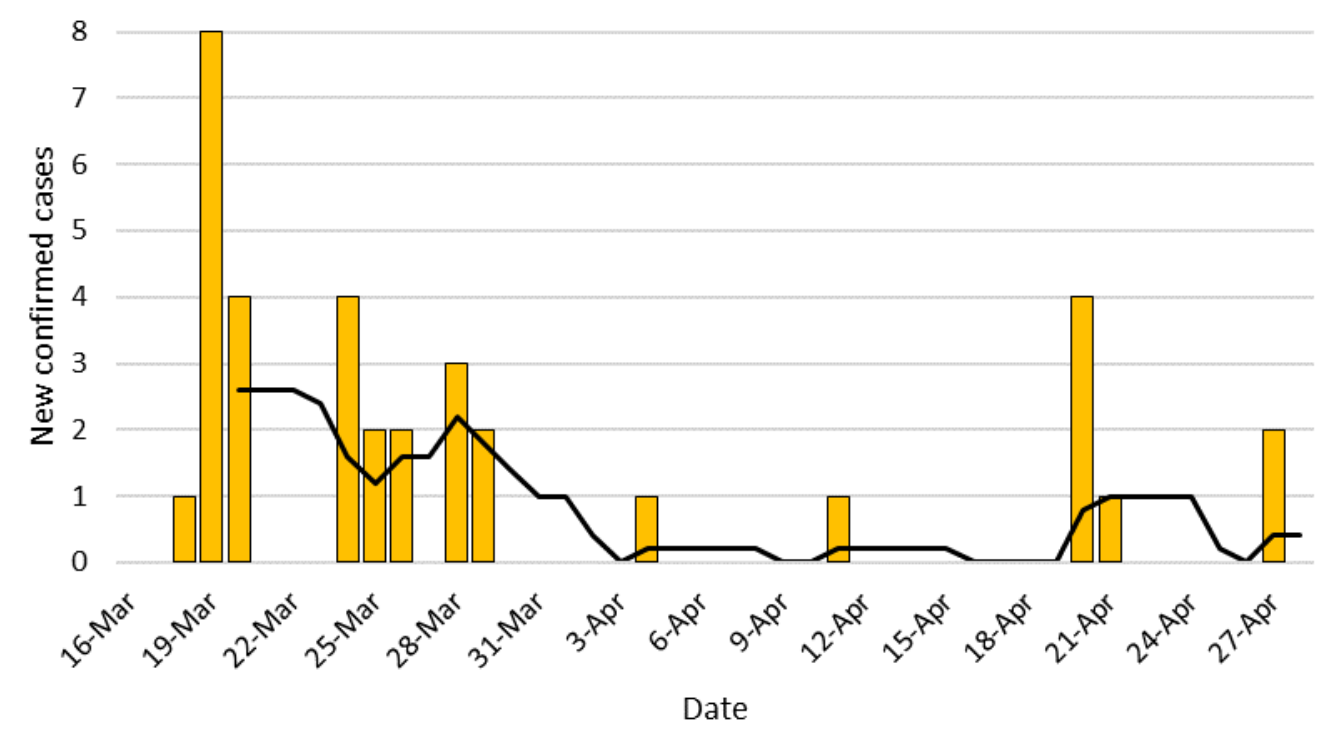

Figure 18: Data highlighting moving average of new confirmed cases over 5 days in Bhilwara, Rajasthan was plotted as a bar graph. The solid black line depicts the trend in occurrence of new cases by removing the noise from random fluctuations

\section{Discussion}

With more than 3 million cases and 0.2 million deaths reported worldwide COVID-19 becomes a serious health issue. India being the second most populous country in the world faces an enormous challenge to control the pandemic. This study was undertaken to enhance our understanding of the virus spread in India. From the data presented, we see that the growth rate of total cases decreased in April due to the strict lockdown being imposed. If no intervention would have been there, we estimate that the cases would have continued doubling every three days and the number of infected people could have reached as high as 27 lakhs. Maharashtra continued to be the most severely affected state, followed by Gujarat and Delhi and a correlation could be established with the population density. The deaths due to co-morbidities in elderly patients proved to be an evolving challenge requiring continuous monitoring. The initiatives taken by the Kerala state government illustrated the effectiveness of strict containment measures on the frequency of infection. The Bhilwara model also highlighted how quick and effective intervention strategies helped contain the spread of the virus. Both these models can be used as useful benchmarks for controlling infections in other states, particularly Maharashtra that continues to report increasing number of cases. We rationalize that while travel bans and the national lockdown are strong contributory factors, varied strategies adopted by different states in terms of aggressive testing, effective isolation of infected individuals and tracking of cases are also key factors impacting the emerging picture of COVID-19 infection in India. 


\section{Acknowledgment:}

The authors acknowledge the support of the management (Tirumala Tirupati Devasthanams), Sri Venkateswara College and University of Delhi.

Conflicts of interest: The authors declare no conflict of interest.

\section{References}

1. Lu H, Stratton CW, Tang YW. Outbreak of pneumonia of unknown etiology in Wuhan China: the mystery and the miracle. J Med Virol 2020.

2. https://covid19.who.int/

3. Wang D, Hu B, Hu C, Zhu F, Liu X, Zhang J, et al. Clinical characteristics of 138 hospitalized patients with 2019 novel coronavirus-infected pneumonia in Wuhan, China. JAMA 2020; 323(11): 1061.

4. Bai Y, Yao L, Wei T, Tian F, Jin DY, Chen L, et al. Presumed asymptomatic carrier transmission of COVID-19. JAMA 2020 [Epub ahead of print].

5. David R. India confirms its first coronavirus case. CNBC. 30 January 2020.

6. Vaidyanathan G. People power: Jow India is attempting to slow the coronavirus. Nature, 580, 23 April 2020 (https://www.nature.com/articles/d41586-020-010585?WT.ec_id=NATURE-

$20200423 \& u t m \_s o u r c e=$ nature_etoc $\& u t m \_$medium $=$email\&utm_campaign=2020042 3\&sap-outbound-id=D4A6F5754D4D34CC1E9370E69414E1392C463959

7. India has 909 active corona cases, total tally crosses 1,000 . Outlook.

8. Coronavirus cases in India cross 20,000; death toll crosses 650. India Today. 22 April 2020.

9. https://www.mohfw.gov.in/

10. https://www.mygov.in/aarogya-setu-app/

11. https://www.sisense.com/glossary/r-analytics/

12. https://www.r-project.org/about.html

13. https://www.datawrapper.de/

14. https://theprint.in/health/one-coronavirus-patient-infects-1-7-people-in-india-muchlower-than-in-china-italy-study/383538/

15. A dictionary of epidemiology, 5th edn. Oxford University Press, Oxford2008 https://www.oxfordreference.com/view/10.1093/acref/9780195314496.001.0001/acre f-9780195314496

16. https://www.livemint.com/news/india/number-of-covid-19-containment-zones-risesto-100-in-delhi-full-list-1158808682

17. https://www.who.int/docs/default-source/coronaviruse/situation-reports/20200418sitrep-89-covid-19.pdf?sfvrsn=3643dd38_2

18. https://pib.gov.in/newsite/bulletinn.aspx

19. https://www.newindianexpress.com/states/kerala/2020/apr/14/kasaragod-initiative-ofkerala-police-once-one-of-indias-biggest-covid-19-hotspots-now-a-model-fo2130041.html

20. https://indianexpress.com/article/explained/explained-bhilwara-model-ruthlesscontainment-stop-coronavirus-6350395/ 